\title{
An Alignment Model for Collaborative Value Networks
}

\author{
Carlos Bremer, Rodrigo Cambiaghi Azevedo, and Alexandra Pereira Klen \\ Axia Consulting, Av. Nações Unidas, 12551, $18^{\circ}$ Andar, 04578-903, \\ São Paulo - SP, Brazil \\ \{carlos.bremer, rodrigo.cambiaghi, \\ alexandra.klen\}@axiaconsulting.com.br
}

\begin{abstract}
This paper presents parts of the work carried out in several global organizations through the development of strategic projects with high tactical and operational complexity. By investing in long-term relationships, strongly operating in the transformation of the competitive model and focusing on the value chain management, the main aim of these projects was the alignment of multiple value chains. The projects were led by the Axia ${ }^{1}$ Transformation Methodology as well as by its Management Model and following the principles of Project Management. As a concrete result of the efforts made in the last years in the Brazilian market this work also introduces the Alignment Model which supports the transformation process that the companies undergo.
\end{abstract}

Keywords: Value Chain, Business Transformation, Alignment Model, Customer Segmentation, Axia Methodology.

\section{Introduction}

For a Collaborative Value Network to succeed one of the main challenges is to guarantee the alignment between customer value proposition and its subsequent value delivery. A careful analysis of some companies' businesses showed that they experience the same main problems: their choices and trade-offs are not converted into execution because their strategies are primarily deployed within departments thus breaking down the value generation flows disperse throughout the organization and consequently increasing the difficulty for decision makers to align themselves.

With this in mind, the key objectives of the discussions carried out in this work are twofold:

- To anticipate, react to and reduce value chain variabilities in the company delivery and value generation flow; and

- To integrate and align value proposition with value delivery.

This paper focuses therefore on presenting the research developed as well as the actions taken for achieving the above mentioned objectives.

The remaining part of this paper is organized as follows: section 2 provides an overview of the Axia Transformation Methodology which arose from the award-winning

${ }^{1}$ Axia in Greek means "Value". 
academic research of the SAP University Alliance Grant Awards. Its prima facie effectiveness allows fundamental dimensions to be wholly and simultaneously developed ensuring long-lasting transformation and excellence in competitiveness and value generation. Section 3 addresses the 7 processes of the Axia Management Reference Model and section 4 shows how the alignment projects are managed according to the Transformation Methodology. In this fourth section it is highlighted how the proposed 7 dimensions of business transformation allow the use of a holistic approach to critical factors of success throughout the course of developing the alignment projects, ensuring that the 6 phases of transformation meet the business objectives proposed. Section 5 depicts the Alignment Model and the main concepts that have guided its development. Finally, section 6 presents some conclusions and the next envisaged steps.

\section{Fundamental Dimensions}

The boom of ERP implementations in the late 90s brought alongside with it a vast level of unsuccessful rate; at least when analyzed through a perspective of the achieved value chain improvements. At that time, as members of an academic institution, we have launched a research question aiming to investigate the causes of the gap between the proposed value of an ERP and the value companies were achieving with its implementation. In January 2000, this research was granted with the SAP University Alliance Awards as the best applied research in Americas and its result is still today a core element of our methodological approach applied in global transformation projects.

In this research, we found out that ERP implementations were always driven by 3 business dimensions: processes, people and information technology. However, through an explorative approach, we have figured out that by applying this 3dimensional perspective in the transformation, projects were leaving behind other vital aspects of a value chain "ecosystem". The research concluded that 7 dimensions drive any complex value chain transformation: vision, strategy, organization, key performance indicators (KPIs) plus the previous three dimensions; people, processes and technology. Till today, and according to the best knowledge of the authors, there is no similar methodology that considers all these 7 dimensions foreseen in the Axia transformation methodology. Figure 1 depicts the 7-dimensions transformation approach and in its sequence each dimension is outlined.

- Vision: in charge of aligning the value expected with proposed transformation among multiple stakeholders across the value chain;

- Strategy: sets and aligns across the organization the steps (e.g. projects, stages, sub-projects) required for the transformation;

- Organization: probably one of the most complex aspects during any value chain transformation, this dimension is responsible to design a new organizational structure better aligned with the future arrangement of the value chain;

- KPIs: it is in charge of setting the most appropriate indicators which will drive the new configuration of the value chain;

- People: deals with the organizational and individual knowledge and skills required for the future scenario; 
- Technology: is the dimension that searches for the best IT solutions in order to support the new business challenges;

- Processes: the set of activities required for carrying out the new work system. This dimension links all previous ones and for this reason it is placed in a central position in Figure 1.

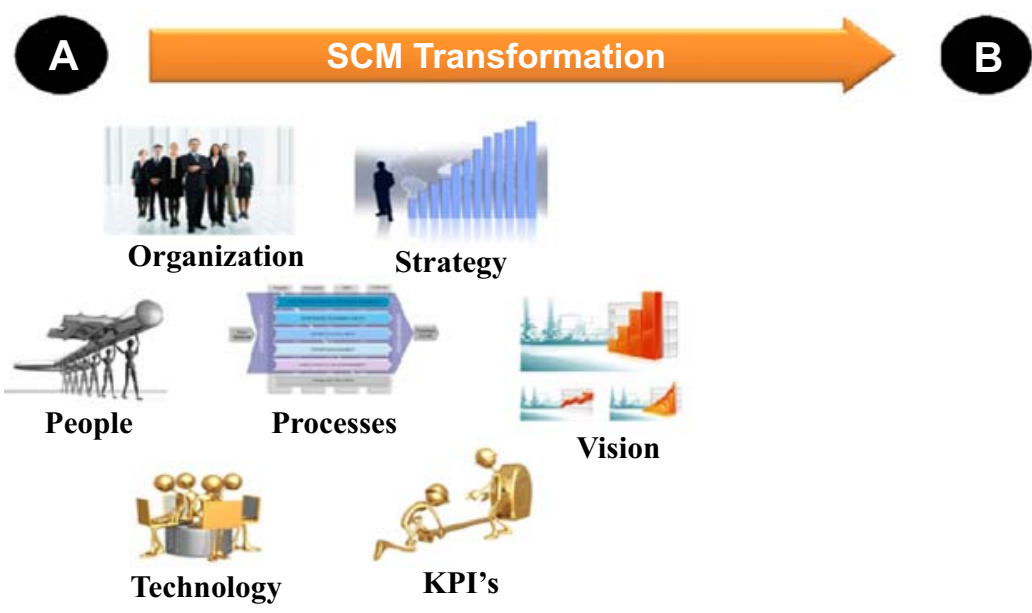

Fig. 1. Seven Dimensions of a Business Transformation

\section{Management Processes Reference Model}

Our academic background alongside with the hands-on experience on several global value chain transformations, allowed us to develop a reference model for managing complex value chains. This model aims to address the important decisions a company faces; from the strategy formulation down to its deployment, execution and follow up.

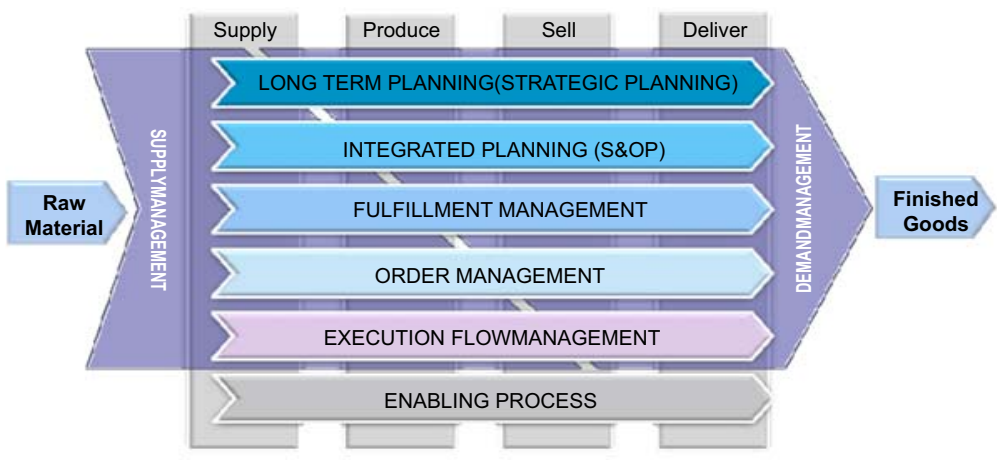

Fig. 2. Axia Management Model 
Figure 2 illustrates the model which is composed of 7 core processes: strategic planning, integrated planning (S\&OP), fulfillment management, order management, execution flow management, supply management and demand management. While the 5 former processes (strategic planning, S\&OP, fulfillment management, order management, and execution flow management) are in charge of deploying and managing strategic drivers through tactical and operational flows, the supply and demand management processes are in charge of pursuing forward and reverse alignments with, respectively, customers and suppliers of a value chain (Bremer et al., 2009) enabling the alignment of the collaborative value network.

\section{Transformation Methodology}

The alignment projects are executed in 6 phases: initiation, visibility, proposition, design, implementation and value capture. The first 3 phases comprise what is called the "Supply Chain Challenges Identification". By applying the 7 fundamental business dimensions (Figure 3) a through ample and in-depth analysis is developed in the companies and a value chain diagnosis is provided together with an action plan that provides clear and concrete recommendations in order to promote value chain transformation. This diagnosis takes in average 12 weeks. The last 3 phases are carried out in the sequence.

The key achievements are usually identified during the phase of value capture. At this stage two kinds of results are perceived: the first one can be measured (very notable improvement in the performance of operations and financial results of the company, for instance); the second can be felt (collaborative value networks are made up of people, and the success of the value chain transformation depends directly on them).

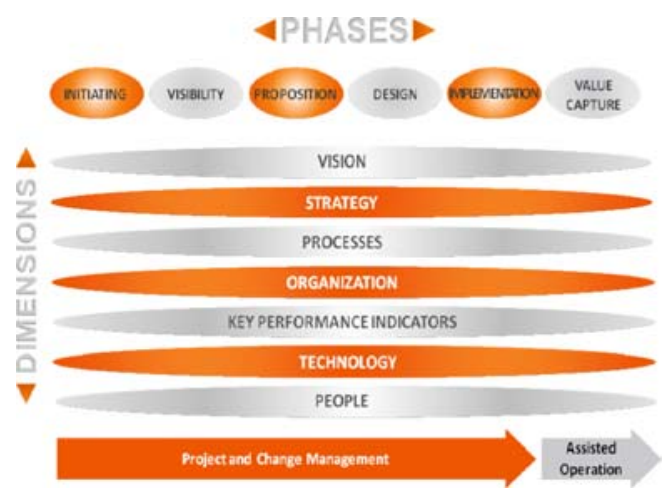

Fig. 3. Axia Transformation Methodology

\section{Collaborative Value Networks}

The breakthrough point in the alignment projects was the awareness that current segmentation approaches do not translate and align the value chain. The variabilities and 
the lack of confidence have to be faced considering that suppliers, producer and clients are part of a collaborative value network (CAMARINHA-MATOS and AFSARMANESH, 2006) and that distributed and collaborative business processes are being managed in a dynamic way (PEREIRA-KLEN et al., 2001; PEREIRA-KLEN and KLEN, 2005; RABELO, PEREIRA-KLEN and KLEN, 2004). This means that value chains come in a number of different forms, and some companies use more than one for different parts of their businesses (GATTORNA, 2006). One chain may run lean to keep inventory costs low, whereas another may be more flexible to enable it to respond to new opportunities as they arise. The very important thing is that different value chains within a single organization must work together so that its global performance can be enhanced.

The challenge therefore was to work towards the development and implementation of a multiple value chain alignment strategy which in turn is based on the segmentation of suppliers and clients according to their dominant behavioural forces. To this end this work has adopted the segmentation model of Gattorna (2006) that takes in to consideration the buying behaviour of the clients (Figure 4) and has extended it also to the suppliers.

After realizing that the improvement of the value chain performance in the projects is a consequence of the dynamic alignment of the multiple value chains that co-exist in the companies, other challenges were identified.

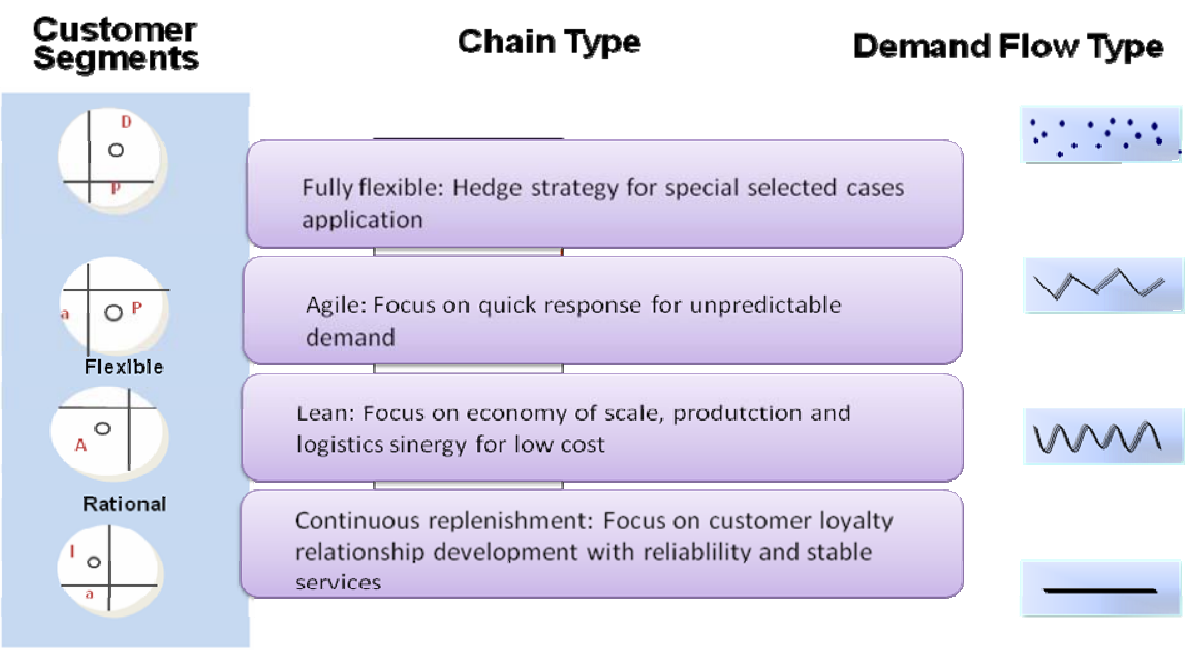

Fig. 4. Segmentation model (GATTORNA, 2006)

The first challenge is to make the companies aware that inside the organization people usually do not have a clear and single vision of the main questions. To clarify this situation in the companies an exercise is proposed and carried out with the executive and tactic managerial levels. In a workshop they should position their business according to what they believe that their competitive strategy is. To this end it is made use of a triadic model (based on a previous work developed by MIT, 2007) that considers: the 
operational efficiency, the customer intimacy and the products (Figure 5, top left). After the usual polarization of opinions of the insiders, the promotion of the alignment of the transformation strategy is stimulated and achieved.

The second challenge is to find an internal agreement about what metrics the companies want to be recognized for by their clients and the market as "best-in-class". To this end it is made use of the SCOR Performance Attributes (Figure 5, top right) defining a set of measurements and establishing internal targets for improvements in processes, functions, products, and so on.

The third challenge is to identify the profile of the companies as well as of their suppliers and clients, according to the segmentation model of Gattorna (Figure 5, bottom). Their behaviour might be classified according to 16 different possible combinations derived from the four dominant behavioural forces, namely:

- $\quad$ Producer (P): the force for action, results, speed and focus.

- Administrator (A): the opposing force to D, and represents stability, control, reliability, measurement, logic and efficiency.

- Developer (D): the force for creativity, change, innovation and flexibility.

- Integrator (I): the opposing force to P, and represents cooperation, cohesion, participation and harmony.

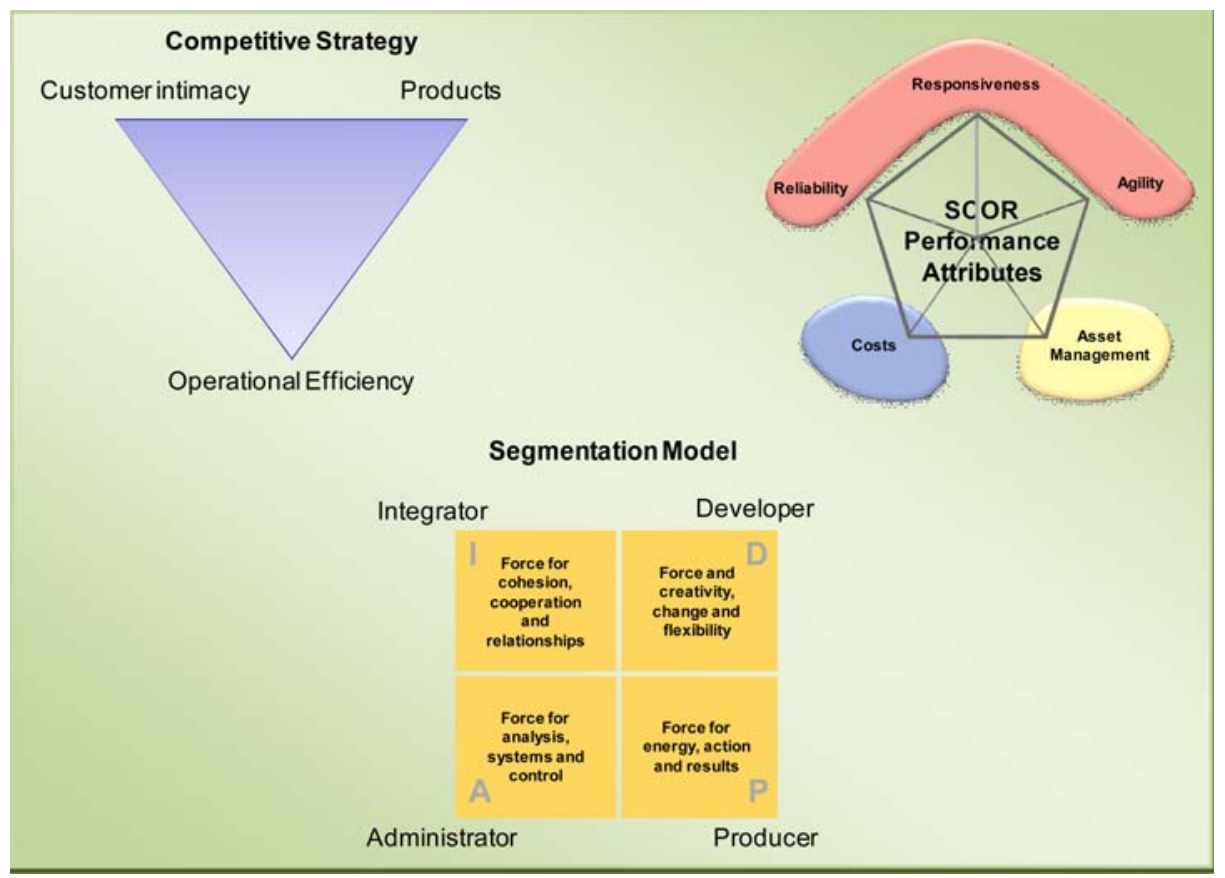

Fig. 5. Alignment challenges 
In order to overcome the challenges and to care for a dynamic alignment of the multiple value chains, an alignment model has been developed (Figure 6). The model combines the triadic model of competitive strategy, the SCOR pentagon of the performance attributes and the "PADI" square of Gattorna. The model shows that companies that are more oriented to operational efficiency present a behavior that tend to be more "producer" (P) or "administrator" (A) usually putting more emphasis on indicators such as costs and asset management. At the same time, companies that have their center of gravity on customer intimacy present a behavior that is predominantly "integrator" (I) and the performance attributes that they mostly care for are reliability and responsiveness. Finally, the model shows that companies that strongly focus on their products behave as "developers" (D) and are more concerned about agility and responsiveness.

This model allows for a better comprehension of the companies situation and therefore speeds up the alignment process of the multiple value chains that flow simultaneously thorough the companies. This understanding and alignment are essential for an adequate and efficient management of collaborative value networks (CAMARINHAMATOS, L. M.; AFSARMANESH, H.; OLLUS, M., 2005).

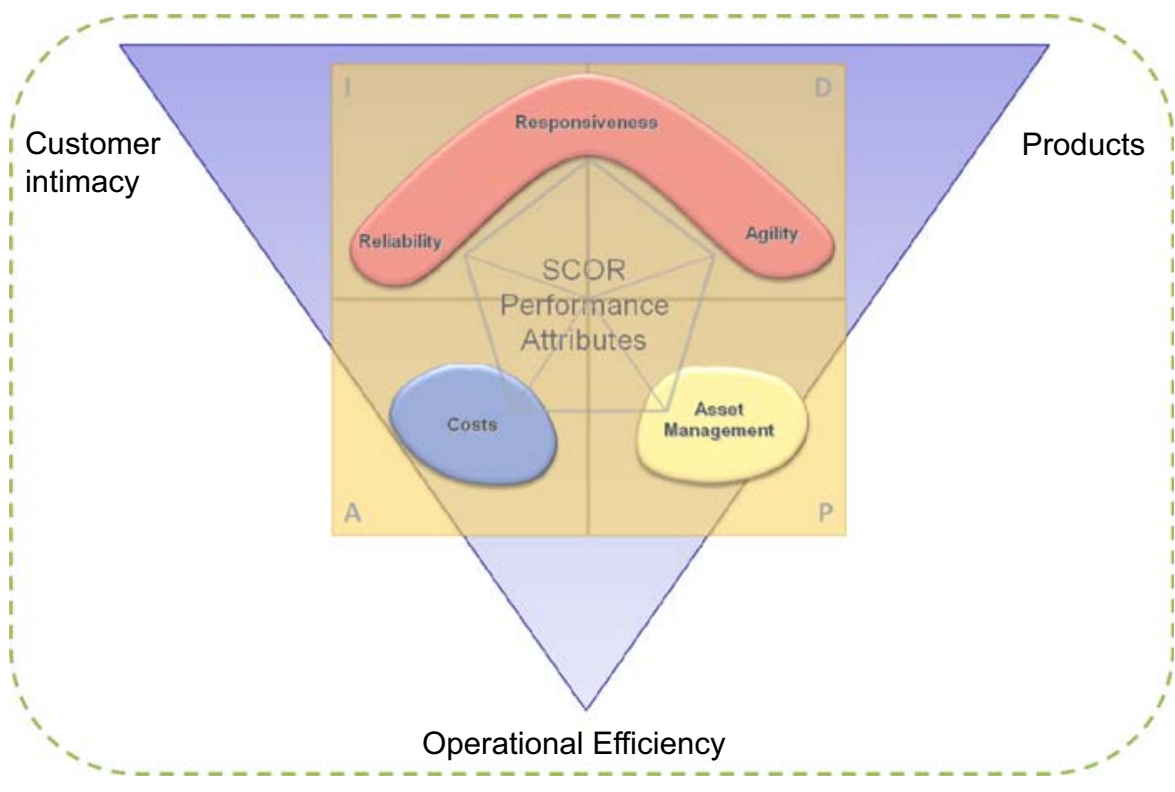

Fig. 6. Alignment Model

\section{Conclusions}

This paper summarizes the achievement of almost ten years of research and work. The whole approach has been maturing during all this time. The research question that was launched almost one decade ago was the trigger for the search for even more 
questions. We are now in the process of finding the answers. Some of them were already found. For collaborative value networks, for instance, we have realized that their management can be significantly improved if the multiple value chains that coexist inside a single company can be aligned. And to this purpose an alignment model was proposed in order to support the transformation process of the companies.

The next planned steps include an analysis on how this alignment model could impact the virtual breeding environment and its members as well as the consideration by the model of performance attributes related to sustainability aspects.

Acknowledgments. Axia Alignment Model has emerged, matured and improved thanks to the joint work performed for and with our customers. The authors thank all Axia's customers for their collaborative spirit as well as the contributions from the whole Axia team.

\section{References}

1. Bremer, C.F., Azevedo, R.C., Aravechia, C., Horta, L.C.: Supply Chain Alignment - Brazilian Style, in Dynamic Supply Chain Alignment - A New Business Model for Peak Performance in Enterprise Supply Chains Across All Geographies. Gower Publishing, London (2009)

2. Camarinha-Matos, L.M., Afsarmanesh, H.: Collaborative networks: Value creation in a knowledge society. In: Wang, K., Kovács, G.L., Wozny, M.J., Fang, M. (eds.) Knowledge Enterprise: Intelligent Strategies in Product Design, Manufacturing and Management, PROLAMAT. IFIP, vol. 207, pp. 26-40. Springer, Heidelberg (2006)

3. Camarinha-Matos, L.M., Afsarmanesh, H., Ollus, M.: Ecolead: A Holistic Approach to Creation and Management of Dynamic Virtual Organizations. In: Camarinha-Matos, L.M., Afsarmanesh, H., Ortiz, A. (eds.) Collaborative Networks and their Breeding Environments. Springer, Heidelberg (2005)

4. Gattorna, J.: Living Supply Chains. Prentice-Hall, Englewood Cliffs (2006)

5. Lapide, L.: Supply Chains Driving Strategic Advantage: Managing Dynamics and Innovating the Future January. MIT-Centre for Transportation and Logistics (2007)

6. Pereira-Klen, A.A., Klen, E.R.: Human Supervised Virtual Organization Management. In: Camarinha-Matos, L.M., Afsarmanesh, H., Ortiz, A. (eds.) Collaborative Networks and their Breeding Environments. Springer, Heidelberg (2005)

7. Pereira-Klen, A.A., Rabelo, R.J., Ferreira, A.C., Spinosa, L.M.: Managing Distributed Business processes in the Virtual Enterprises. Journal of Intelligent Manufacturing 12(2) (April 2001) ISSN 0956-5515

8. Rabelo, R.J., Pereira-Klen, A.A., Klen, E.R.: Effective Management of Dynamic and Multiple Supply Chains. International Journal of Networking and Virtual Organizations 2(3), 193-208 (2004) 